Article

Subscriber access provided by King Abdullah University of Science and Technology Library

\title{
Improving the Compatibility of Diketopyrrolopyrrole (DPP) Semiconducting Polymers for Biological Interfacing by Lysine Attachment
}

Weiyuan Du, David Ohayon, Craig Combe, Lorene Mottier, luliana P.

Maria, Raja S. Ashraf, Hubert Fiumelli, Sahika Inal, and lain McCulloch

Chem. Mater., Just Accepted Manuscript • DOI: 10.1021/acs.chemmater.8b02804 • Publication Date (Web): 17 Aug 2018

Downloaded from http://pubs.acs.org on August 26, 2018

\section{Just Accepted}

"Just Accepted" manuscripts have been peer-reviewed and accepted for publication. They are posted online prior to technical editing, formatting for publication and author proofing. The American Chemical Society provides "Just Accepted" as a service to the research community to expedite the dissemination of scientific material as soon as possible after acceptance. "Just Accepted" manuscripts appear in full in PDF format accompanied by an HTML abstract. "Just Accepted" manuscripts have been fully peer reviewed, but should not be considered the official version of record. They are citable by the Digital Object Identifier (DOI®). "Just Accepted" is an optional service offered to authors. Therefore, the "Just Accepted" Web site may not include all articles that will be published in the journal. After a manuscript is technically edited and formatted, it will be removed from the "Just Accepted" Web site and published as an ASAP article. Note that technical editing may introduce minor changes to the manuscript text and/or graphics which could affect content, and all legal disclaimers and ethical guidelines that apply to the journal pertain. ACS cannot be held responsible for errors or consequences arising from the use of information contained in these "Just Accepted" manuscripts. 


\section{Introduction}

Organic bioelectronics is the convergence of organic electronics and biology. One focus of this field is to develop organic electronic devices that record biological signals or stimulate biological tissues. ${ }^{1-3}$ Motivated by the unique combination of both electronic and ionic conductivity, organic semiconducting materials have been applied in organic electrochemical transistors (OECTs) for sensing applications to translate biological signals into a quantitative electrical reading. ${ }^{4-6}$ Due to their carbon-based structure and flexibility, conjugated polymers (CPs) can achieve improved biocompatibility compared to inorganic devices as they are intrinsically "softer", avoiding mechanical mismatch and the need for surface compatibilizing layers. ${ }^{7-9}$ These promising materials have broad potential to be used in applications such as biosensors, drug delivery, and neural interfaces. ${ }^{10}$ The current state of the art active material used in organic bioelectronics is the commercially available poly (3,4-ethylenedioxythiophene) doped with poly (styrene sulfonate) (PEDOT:PSS) employed mainly due to its availability and acceptable performance. ${ }^{11}$ However, PEDOT:PSS is intrinsically acid doped, suffers from long-term effects of degradation due to the high acidity of residual sulfonate protons of PSS. ${ }^{12}$ Additionally, the semiconductor surface requires treatment with biomolecules, e.g., the extracellular matrix proteins as well as synthetic biomolecules such as poly-ethyleneimine and isomers of poly-lysine, ${ }^{13-14}$ to improve biocompatibility and promote integration with cells. ${ }^{15-16}$

While coating these biomolecules on large area conducting polymer surfaces is not troublesome, a vast majority of bioelectronics applications utilize micrometer scale devices, therefore small area coatings, to communicate with living systems at a single cell level. Moreover, for long term applications, attaching biomolecules covalently on the surface is desired. ${ }^{17}$ Ideally, biological coatings should ensure that cell adhesion occurs on the functional parts of the electronic chip and thus often times they have to be patterned such that the coating is localized on the active area. ${ }^{18-19}$ Moreover, the biological coating not only adds an extra step for the fabrication of the device, although a few nanometers thick, it acts as an insulating layer separating the living system from the electronic transducer. Hence, new semiconducting, conjugated polymers that combine optical and electronic functionalities with enhanced cell adhesion and good biocompatibility for neural interfaces are on demand. Poly-L-lysine (PLL) is commonly used as a coating material in bioelectronic devices, coated on glass or silicone substrates to improve adhesion of cells (typically, neurons). PLL's protonated amino groups increase electrostatic bond formation between the negative charges of the cell membrane and the polycationic layer. ${ }^{15}$ A lysine-functionalized semiconducting polymer may serve as both electrically active, transducing material and interface compatibilizer, thus while readily rendering the surface ideal for cell attachment, it reduces the distance between conjugated polymer film and cells.

Diketopyrrolopyrrole (DPP)-based polymers have been demonstrated as excellent semiconducting candidates for charge transport. ${ }^{20-22}$ The copolymer of dithienyldiketopyrrolopyrrole and thiophene (DPP3T) was therefore selected as the semiconducting backbone due to its high charge carrier mobility and facile chemical functionalization. However, the strong hydrogen bonding properties of lysine gives rise to strong intermolecular aggregation which insolubilize polymers that contain these units on their side chains. We, therefore, synthesised tert-Butyloxycarbonyl (BOC) pro- 
tected side chain DPP3T polymers (Figure 1), which suppress-
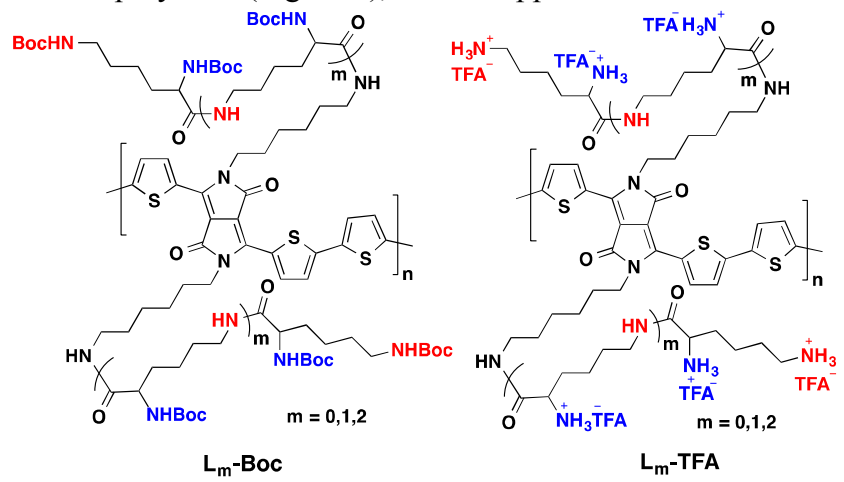

these

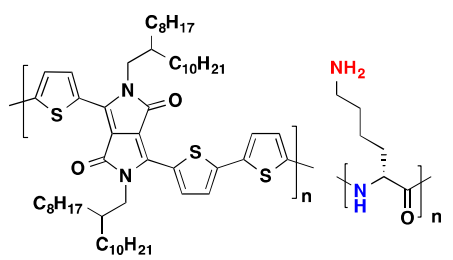

Figure 1. The molecular structures of lysinated-DPP3T, alkyl DPP3T-C $\mathrm{C}_{8,12}$ and polylysine.

\section{Scheme 1. Synthesis Routes of the Lysinated-DPP3T polymers.}
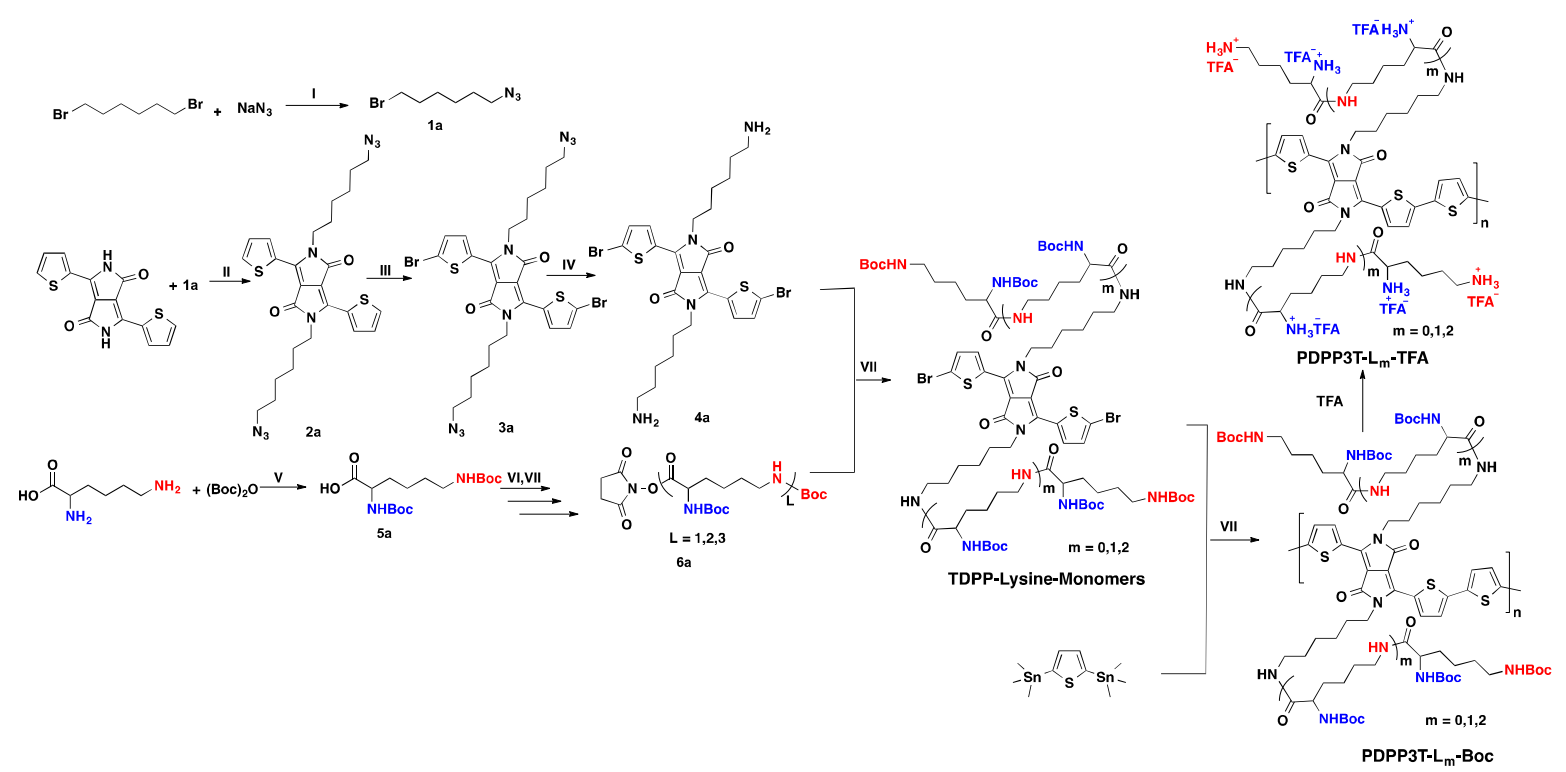

Poly-L-Lysine

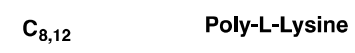

${ }^{\mathrm{a}}$ Reaction conditions: (I) DMSO, at r.t.; (II) $\mathrm{K}_{2} \mathrm{CO}_{3}$, DMF, $120^{\circ} \mathrm{C}$; (III) NBS, $\mathrm{CHCl}_{3} / \mathrm{AcOH}$ (10:1), dark at r.t.; (IV) $\mathrm{PPh}_{3}, \mathrm{CHCl}_{3} / \mathrm{THF}^{\circ} \mathrm{H}_{2} \mathrm{O}$ (10:10:1); (V) $\mathrm{THF} / \mathrm{H}_{2} \mathrm{O}(1: 1), 0{ }^{\circ} \mathrm{C}$ and then $50{ }^{\circ} \mathrm{C}$; (VI) DCM, $0{ }^{\circ} \mathrm{C}$ to r.t.; (VII) $\mathrm{NaHCO}_{3}$ in $\mathrm{THF} / \mathrm{H}_{2} \mathrm{O}$ (1:1) r.t; (VIII) DMF, $80{ }^{\circ} \mathrm{C}, 24 \mathrm{~h}$.

polymer solubility and can subsequently undergo deprotection by trifluoroacetic acid (TFA) to reveal protonated lysine units (Figure 1). BOC pro tection was also found to be necessary in order to facilitate Stille polymerization. Lysine has both an $\varepsilon$-amino and $\alpha$-amino group, which, when coupled, afford two isomers. The $\varepsilon$-lysine isomer was chosen as functional group over the $\alpha$-lysine analogue, as it provided a relatively lower contact angle. Polymers containing multiple lysine units (from 1 to 3 ) on the terminal position of the side chains (Figure 1) were synthesized to evaluate the effect of lysine density on thin film properties. Deprotection was then carried out on the polymer with the addition of TFA solution, which removed the BOC groups and protonated the lysine side chains. This in turn increased the surface charge and improved the cell adhesion

\section{Experimental Section}

\section{Synthesis of Lysinated-DPP polymers.}

The synthesis of Lysinated-DPP polymers is reported in Supporting Information.

Transistor Fabrication and Characterization.
Organic field effect transistors (OFETs) were fabricated in the bottom-contact and bottom-gate configuration. The lysinated DPP3T polymers were dissolved in DMF, spin coated at $1000 \mathrm{rpm}$ for $2.5 \mathrm{~min}$ then $2000 \mathrm{rpm}$ for $30 \mathrm{~s}$. The film of DPP3T- $\mathrm{C}_{8,12}$ was spun from a chloroform solution at $1000 \mathrm{rpm}$ for 30s. Freshly prepared devices were annealed at $50{ }^{\circ} \mathrm{C}$ for 15 mins to remove traces of solvents. The substrates were purchased from Fraunhofer. They are n-doped silicon (doping at wafer surface: $\mathrm{n} \sim 3 \cdot 10^{17} \mathrm{~cm}^{-3}$ ), $150 \mathrm{~mm}$ wafer according to SEMI standard (675 $\pm 20 \mu \mathrm{m}$ thickness). Gate oxide is $230 \pm 10 \mathrm{~nm} \mathrm{SiO}_{2}$ (thermal oxidation).

Contact angle. Contact angles on glass substrates coated with lysinated-DPP3T polymers, reference DPP3T- $\mathrm{C}_{8,12}$ and PLL were measured by the manual drop method. For each film, measurements were carried out and at least 10 drops were measured.

Atomic Force Microscopy (AFM). AFM imaging was performed on a Dimension Icon Spm equipped with a Nanoscope $\mathrm{V}$ controller and type $\mathrm{E}$ and $\mathrm{J}$ piezoelectric scanners (Bruker, USA). Samples were scanned in Tapping mode with FESAPA-75 probes (Bruker, USA) in air. Background 
interpolation and surface roughness parameter calculation were performed with Gwyddion 2.49 (http://gwyddion.net/).

MALDI-TOF. MALDI-TOF spectrometry was conducted in positive linear mode on a Micromass MALDImxTOF with trans-2-[3-(4-tert-butylphenyl)-2-methyl-2-propenylidene]malononitrile (DCTB) as the matrix.

Electrochemical characterization. Characterization was performed for polymers that are spin-coated on interdigitated microelectrodes exposed to $0.1 \mathrm{M} \mathrm{NaCl}$ aqueous solutions in ambient air conditions. All substrates were washed in an ultrasonic bath for 15 minutes both in water and acetone/isopropanol prior to the polymer film deposition. The different polymer solutions were spin-coated $\left(3 \mathrm{gmL}^{-1}, 1000\right.$ rpm for $2.5 \mathrm{~min}$ then $2000 \mathrm{rpm}$ for $30 \mathrm{~s}$ ) on the two-terminal (working electrodes 1 and 2) gold interdigitated microelectrode array fabricated on glass substrate (Micrux Technologies, Figure 8a). CV measurements were recorded using a bipotentiostat-galvanostat (Autolab, PGSTAT128N) with an $\mathrm{Ag} / \mathrm{AgCl}$ reference electrode and a Pt counter electrode. CV curves were acquired at a scan rate of $50 \mathrm{mVs}^{-1}$. For in situ conductance measurements, we use the bipotentiostat module, measuring the current flowing between the two contacts (working electrodes WE1 and WE2) while retaining a fixed bias of $30 \mathrm{mV}$ between them at a scan rate of $10 \mathrm{mVs}^{-1}$. The conductance curves were obtained from the current flowing between the two electrodes $\left(\mathrm{I}_{\Omega}\right)$ as in the following ${ }^{23}$ :

$$
\mathrm{I}_{\Omega}=\frac{\mathrm{I}_{\mathrm{WE} 2}-\mathrm{I}_{\mathrm{WE} 1}}{2}
$$

where $I_{\mathrm{WE} 2}$ and $\mathrm{I}_{\mathrm{WE} 1}$ correspond to the current of the WE2 and the WE1, respectively. To obtain conductance $(\sigma)$ value:

$$
\sigma=\left(\frac{\mathrm{I}_{\Omega}}{\mathrm{V}_{\Omega}}\right) *\left(\frac{D}{n * L * T}\right)
$$

Where $\mathrm{V}_{\Omega}$ is the offset potential $(30 \mathrm{mV}), \mathrm{D}$ is the gap between interdigitated microelectrodes $(10 \mu \mathrm{m}), \mathrm{n}$ is the number of individual microelectrodes (180), $\mathrm{L}$ is the electrode length $(1.375 \mu \mathrm{m})$ and $\mathrm{T}$ is the film thickness (in $\mathrm{nm}$ ) as measured by a NT-MDT AFM. The curves correspond to the average values of at least three different measurements.

Cell culture. Cortical neurons were isolated from mouse embryos (E17) (CD-1 IGS mouse, Charles river laboratories) as previously described. ${ }^{24}$ Primary neuronal culture was plated in 24-well plate at a concentration of $0.125 \times 10^{6}$ cells. Each well contained a coverslip previously coated by the polymers and disinfected for 30 minutes in $70 \%$ ethanol. Primary neuronal cells were maintained in Neurobasal A media (Invitrogen, Gibco) supplemented with B-27 (Invitrogen, Gibco) and 0.5mM L-Glutamine (Sigma). Culture was incubated in humidified incubator at $37{ }^{\circ} \mathrm{C}$ and $5 \% \mathrm{CO}_{2}$ and used at different time points. For the viability assays, after 3 , $6,11,14$ and 21 days, neurons were incubated with $0.4 \%$ Trypan Blue solution (Invitrogen) for $30 \mathrm{~min}$ at $37^{\circ} \mathrm{C}$. Then, cells were counted using bright-field microscope with $20 \mathrm{x}$ objective and 10x ocular (magnification 200x). Nonviable cells were stained in dark blue. Three different locations were counted per well. The relative viability assay data correspond to the average of 3 samples for each film and per days of culture. Note that due to the sensitivity of neuronal cells, we could not monitor the cell growth over 21 days on a single sample. We rather cultured the cells on multiple samples of each film and discarded the film once it was used for imaging. Therefore, different films that have been kept in the incubator were used for imaging at the observation day.

\section{Results and Discussion}

In order to demonstrate the necessity of covalent coupling of the lysine units at the peripheral positions of the polymer sidechain, we followed two typical routes to functionalize the polymer with lysine units. The first one, is simply blending of these two components, whereas the second approach involved sequential coating of PLL on top of an unfunctionalized polymer to form a bilayer. The unfunctionalized DPP3T polymer that was used to make the blend and bilayer films was a branched long chain alkyl analogue, DPP3T$\mathrm{C}_{8,12}$. It was, however, not possible to fabricate a blend film with appropriate homogeneous microstructure from a solution comprising a mixture of PLL with DPP3T- $\mathrm{C}_{8,12}$, mainly due to the differences in polarity of the two polymers resulting in de-mixing occurring at the micrometer length-scale, as was observed in the electron energy loss spectroscopy (EELS) images shown in Figure 2b. In contrast, a homogeneous distribution of carbon and sulfur was achieved (Figure 2a) for the neat DPP3T- $\mathrm{C}_{8,12}$ polymer. We suspect that the lack of a common solvent for dissolution of the two polymers at the required solution concentration for thin film coating contributed to film reticulation on coating and incoherent substrate coverage, which could not be improved via protocols for the optimization of processing conditions. Such phase separation and poor film quality are extremely detrimental to electrical transport and can also lead to inhomogeneous surface adhesion. Consequently, the blending approach was concluded to be unsuitable for biocompatibility of DPP3T-C 8,12 .

Fabrication of a DPP3T- $\mathrm{C}_{8,12}$ and PLL bilayer was also not possible, either by spin coating or drop-casting of a PLL solution on top of a thin film of DPP3T- $\mathrm{C}_{8,12}$. Drop-casting of PLL caused DPP3T- $\mathrm{C}_{8,12}$ film delamination, whereas for spin coating, as can be seen in the X-ray photoelectron spectroscopy (XPS) depth profiling in Figure S1, sulphur (only present in DPP3T) was observed uniformly throughout the surface of the film indicating the absence of a defined interface between the two polymers. For this reason, the bilayer approach was also concluded to be not suitable. Preparation of a lysine containing semiconducting DPP3T polymer therefore required a covalent polymer approach with lysine groups directly attached to the semiconducting polymer along the backbone as graft units on the periphery of the side chains. Good quality thin films with a high lysine to DPP volume fraction can be readily prepared from such lysinatedDPP3T polymers.
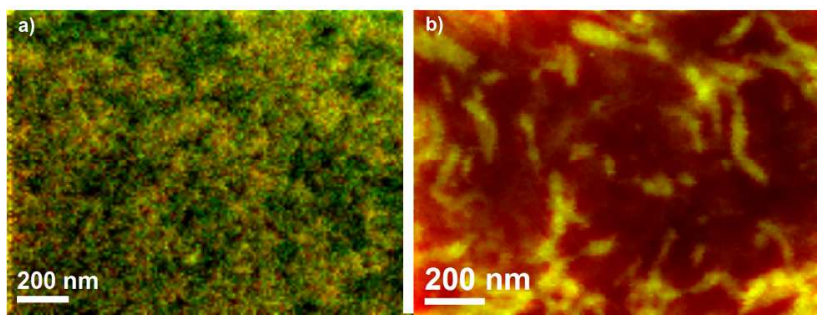
Figure 2. ELLS images of: a) DPP3T- $\mathrm{C}_{8,12}$; b) Blend of DPP3T$\mathrm{C}_{8,12}$ and PLL. Carbon is red, sulfur is green.

Table 1. Properties of Polymers

\begin{tabular}{|c|c|c|c|c|c|c|}
\hline \multirow{2}{*}{ DPP3T } & \multirow{2}{*}{$M w^{a}$} & \multirow{2}{*}{$\begin{array}{l}\text { Number of } \\
\text { repeat units }\end{array}$} & \multicolumn{2}{|c|}{$\lambda_{\max (\mathrm{nm})}$} & \multirow{2}{*}{$\begin{array}{c}\text { Ionisation } \\
\text { Potential }(\mathrm{eV})^{d} \\
\end{array}$} & \multirow{2}{*}{$\begin{array}{c}\text { Electron } \\
\text { Affinity }(\mathrm{eV})^{e}\end{array}$} \\
\hline & & & Solution $^{b}$ & As cast $^{c}$ & & \\
\hline $\mathrm{C}_{8,12}$ & $12.2 \mathrm{k}$ & 13 & $806 / 758$ & $842 / 769$ & -5.2 & -3.8 \\
\hline $\mathrm{L}_{0}$-TFA & $7.9 \mathrm{k}$ & 6 & $837 / 793$ & $831 / 781$ & -5.0 & -3.7 \\
\hline $\mathrm{L}_{1}-\mathrm{TFA}$ & $12.6 \mathrm{k}$ & 7 & 819 & 802 & -5.1 & -3.8 \\
\hline $\mathrm{L}_{2}$-TFA & $11.5 \mathrm{k}$ & 5 & 770 & 789 & -5.1 & -3.8 \\
\hline $\begin{array}{l}{ }^{a} \text { Determin } \\
\text { BOC, calc } \\
\text { PESA. }{ }^{e} \text { Es }\end{array}$ & $\begin{array}{l}\text { Matr } \\
\text { d as D } \\
\text { ed by }\end{array}$ & $\begin{array}{l}\text { ted laser de } \\
{ }_{\mathrm{m}} \text {-TFA. }{ }^{b} \mathrm{M} \\
\mathrm{n} \text { of the abs }\end{array}$ & $\begin{array}{l}\text { /ionizat } \\
\text { in dilut } \\
\text { onset to }\end{array}$ & $\begin{array}{l}\text { f flight } \\
\text { at } 25^{\circ} \mathrm{C} \\
\text { tion Pot }\end{array}$ & $\begin{array}{l}\text { metry (MALD } \\
\text { l-coated from } 3\end{array}$ & $\begin{array}{l}\text { on DPP3T-L } \\
\text { aL. }{ }^{d} \text { Measured }\end{array}$ \\
\hline
\end{tabular}

The synthesis of the lysinated DPP3T polymers is shown in Scheme 1 and further described in the Supporting Information. It was not possible to polymerise lysine containing DPP monomers without protecting the free amine groups with tertButyloxycarbonyl (BOC), which provides the required solubility in the DMF polymerization solvent. To incorporate lysine side-chains on the conjugated polymer, a thienyl-DPP (TDPP) monomer containing amine functionality was synthesized by firstly obtaining the asymmetric 1-azido-6-bromohexane (1a) from 1,6-dibromohexane and sodium azide. This product was then used to alkylate TDPP by standard $\mathrm{S}_{\mathrm{N}} 2$ procedure using potassium carbonate base in DMF (2a). 2a was then brominated on the 5-position of both thiophenes using $\mathrm{N}$ Bromosuccinimide (NBS) in the absence of light (3a), followed by reduction of the azide to amine (4a) with triphenyl phosphine. One, two, and three lysine unit oligomers containing the reactive $\mathrm{N}$-Hydroxysuccinimide (NHS) ester group were all synthesized via combinations of BOC protection, esterification and amidation. The NHS ester (6a) was then condensed with the amine containing DPP (4a) to afford the lysine monomers. 2,5-bis(trimethylstannyl)thiophene was used as co-monomer for the synthesis of DPP3T- $\mathrm{L}_{\mathrm{m}}-\mathrm{BOC}(\mathrm{m}=0,1$, 2) using Stille cross coupling conditions described in the SI. For DPP3T- $\mathrm{L}_{\mathrm{m}}$-BOC, only low molecular weight polymer could be obtained, which was attributed to the poor solubility of the growing polymer and potential chelation of the catalyst with the polar functionality of the lysine units. The molecular weight of all polymers is reported as measured by Matrixassisted laser desorption/ionization time of flight spectrometry (MALDI-TOF). It is likely that this is an underestimation of the true polymer molecular weight, due to limitations of longer chain lengths to "fly". As is common with aromatic polymers containing polar side chains, intermolecular aggregation in solution GPC measurement calibrations to greatly overestimate molecular weight values. ${ }^{25}$ For comparison, GPC values are shown in Table 1 of the SI. Alkyl DPP3T-C ${ }_{8,12}$ was synthesized following a literature protocol. ${ }^{21}$ Due to its good solubility in common organic solvents, GPC was also used to determine molecular weight and the results could be compared with MALDI-TOF. It was interesting to note that the molecular weight value determined from GPC was about twice that of MALDI-TOF, consistent with other literature observations. Finally, an excess of TFA was added to the DPP3T- $\mathrm{L}_{\mathrm{m}}-\mathrm{BOC}$ solution to deprotect the BOC groups, generating lysine units with positive charged amine as DPP3T- $\mathrm{L}_{\mathrm{m}}$-TFA $(\mathrm{m}=0,1,2)$.
The optical properties of all polymers were characterized by $\mathrm{UV}$-vis absorption spectroscopy in solution and in thin film (Figure S2). The primary broad absorption at around $800 \mathrm{~nm}$ for all polymers is attributed to $\pi-\pi^{*}$ transition, with a corresponding S0-S1 shoulder transition at $400 \mathrm{~nm} .^{26}$ In solution, DPP3T- $\mathrm{L}_{0}$-TFA displayed a maximum absorption at $837 \mathrm{~nm}$ and an additional vibronic shoulder at $793 \mathrm{~nm}$, attributed to aggregation (Figure S2). There was less aggregation observed in solution for the two longer lysine containing polymers, with DPP3T- $\mathrm{L}_{1}$-TFA and DPP3T- $\mathrm{L}_{2}$-TFA respectively displaying an absorption maximum at $819 \mathrm{~nm}$ and $770 \mathrm{~nm}$. DPP3T-C $\mathrm{C}_{8,12}$ exhibited a solution absorption maximum of $806 \mathrm{~nm}$ and a corresponding vibronic shoulder at shorter wavelength. All lysinated polymers displayed similar spectra in the solution and solid-state UV, indicating significant solution aggregation. Furthermore, DPP3T-L $\mathrm{L}_{1}$-TFA exhibited a $17 \mathrm{~nm}$ blue shift in the solid state, in comparison to the solution spectra, likely originating from reduced packing, due to the presence of the bulky TFA counter ions. On the other hand, the solid-state spectra of DPP3T- $\mathrm{L}_{2}$-TFA, and in particular of DPP3T- $\mathrm{C}_{8,12}$, showed a red shift, suggesting increased solid state planarization of the backbone. The ionization potential of all polymers was determined by photoelectron spectroscopy in air (PESA). DPP3T- $\mathrm{L}_{\mathrm{m}}$-TFA $(\mathrm{m}=0,1,2)$ polymers exhibited a slightly lower ionization potential than the branched alkyl analogue, attributed to the local ionic environment. In combination with thin-film optical absorption measurements, a band gap of 1.3 $\mathrm{eV}$ was calculated (Table 1). DPP3T- $\mathrm{C}_{8,12}$ exhibited an ionization potential of $-5.2 \mathrm{eV}$ with a band gap of $1.4 \mathrm{eV}$.

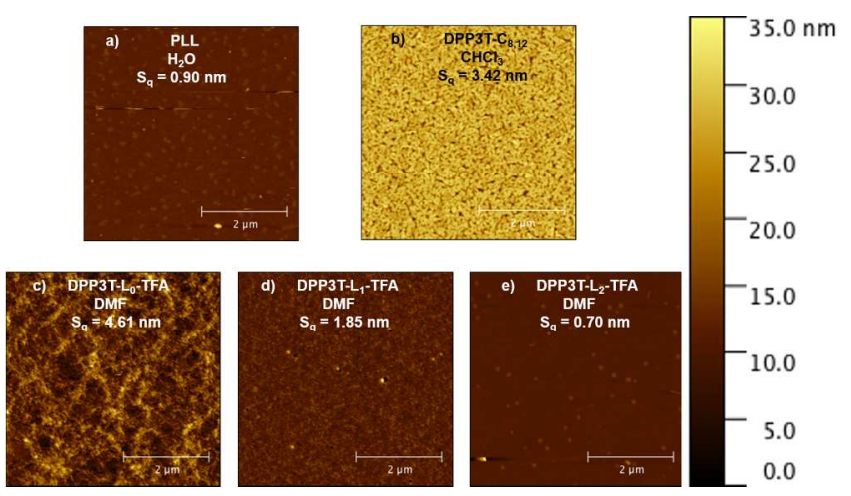

Figure 3. Tapping mode AFM height images of polymer films cast from a range of solvents. 
One important substrate property governing cell adhesion and growth is the surface charge. A quantification of this surface charge is the zeta potential, summarized for all polymers in Table 2 . The DPP3T-C $\mathrm{C}_{8,12}$ reference polymer exhibits a negatively charged surface of $-50.87 \pm 3.97 \mathrm{mV}$, whereas a dropcast PLL layer exhibits a zeta potential of $(49.69 \pm 0.89 \mathrm{mV})$. For lysinated-DPP3T polymers, increasing the lysine units on side chain results in an increasingly positively charged surface, with DPP3T- $\mathrm{L}_{2}$-TFA achieving a value of $29.73 \pm 4.63 \mathrm{mV}$, approaching that of PLL. Another important factor for cell adhesion is the surface roughness, as micron-scale topographical features have been shown to inhibit cell growth. ${ }^{18}$ PLL (drop casted) and DPP3T-C 8,12 (Figure 3a,b) exhibited a quadratic mean roughness $\left(S_{\mathrm{q}}\right)$ of $0.90 \mathrm{~nm}$, and $3.42 \mathrm{~nm}$, respectively. All DPP3T- $\mathrm{L}_{\mathrm{m}}$-TFA films were spun from a DMF solution. DPP3T-L ${ }_{0}$-TFA exhibits a slightly higher surface roughness $\left(S_{\mathrm{q}}=4.69 \mathrm{~nm}\right)$ due to its low solubility in DMF (Figure $3 c)$. The more soluble DPP3T- $\mathrm{L}_{1}-\mathrm{TFA}$ and DPP3T- $\mathrm{L}_{2}-\mathrm{TFA}$ films, on the other hand, exhibit a roughness of $1.85 \mathrm{~nm}$ and $0.70 \mathrm{~nm}$, respectively (Figure $3 \mathrm{~d}, \mathrm{e}$ ). In all cases however, it is not expected for these films that surface roughness plays an important role in cell adhesion.

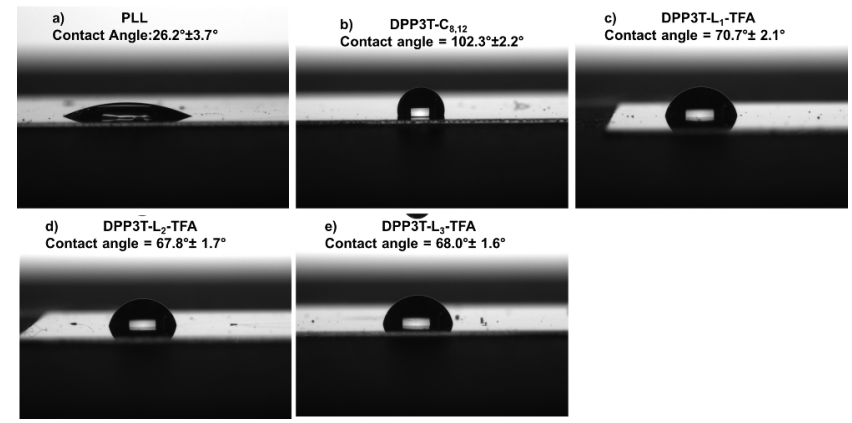

Figure 4. Water contact angle measurements for polymer thin films cast from a range of solvents. All films were cast from DMF except for DPP3T-C 8,12 and PLL, cast from chloroform and water, respectively.

Table 2. Zeta Potential, Surface Roughness and Contact

\begin{tabular}{cccc}
\hline Polymers & $\begin{array}{c}\text { Zeta Potential } \\
(\mathrm{mV})^{\mathrm{a}}\end{array}$ & $\begin{array}{c}\text { Surface } \\
\text { Roughness }(\mathrm{nm})^{\mathrm{b}}\end{array}$ & Contact angle $^{\mathrm{c}}$ \\
\hline PLL & $+49.69 \pm 0.89$ & 0.90 & $26.2^{\circ} \pm 3.7^{\circ}$ \\
$\mathrm{C}_{8,12}$ & $-50.87 \pm 3.97$ & 3.42 & $102.3^{\circ} \pm 2.2^{\circ}$ \\
$\mathrm{L}_{0}$-TFA & $-44.17 \pm 11.49$ & 4.61 & $70.7^{\circ} \pm 2.1^{\circ}$ \\
$\mathrm{L}_{1}$-TFA & $+3.56 \pm 1.71$ & 1.85 & $67.8^{\circ} \pm 1.7^{\circ}$ \\
$\mathrm{L}_{2}$-TFA & $+29.73 \pm 4.63$ & 0.70 & $68.0^{\circ} \pm 1.6$
\end{tabular}

${ }^{\mathrm{a}}$ Measured in $10 \mathrm{mM} \mathrm{NaCl}$ as electrolyte. ${ }^{\mathrm{b}}$ Measured by AFM.

${ }^{\mathrm{c}}$ Measured from water.

angle of PLL and DPP3T polymers
The hydrophilicity of these surfaces was also evaluated. Water contact angles on glass substrates coated with PLL, DPP3T$\mathrm{C}_{8,12}$ and lysinated-DPP3T polymers were measured (Figure 4). PLL is hydrophilic, with a correspondingly low contact angle of $26.2^{\circ} \pm 3.7^{\circ}$, whereas DPP3T-C $\mathrm{C}_{8,12}$ is hydrophobic with a contact angle of $102.3^{\circ} \pm 2.2^{\circ}$ (Figure $4 \mathrm{a}, \mathrm{b}$ ). DPP3T- $\mathrm{L}_{0}$-TFA, with a single lysine unit, exhibited a contact angle value of $70.7^{\circ} \pm 2.1^{\circ}$ when spun cast from a DMF solution (Figure $4 \mathrm{c}$ ). DPP3T-L ${ }_{1}$-TFA and DPP3T- $\mathrm{L}_{2}$-TFA, with more lysine units on the side chain, achieved slightly decreased contact angle values of $67.8^{\circ} \pm 1.7^{\circ}$ and $68.0^{\circ} \pm 1.6$, respectively (Figure $4 d, e$ ). This observation suggests that grafting more than one lysine unit on the side chain does not further improve polymer hydrophilicity.

All DPP3T- $\mathrm{L}_{\mathrm{m}}$-TFA $(\mathrm{m}=0,1,2)$ polymers exhibited mass loss above $100{ }^{\circ} \mathrm{C}$. This is due to TFA counter ions volatilisation $^{27}$. The mass loss from $100{ }^{\circ} \mathrm{C}$ to $250{ }^{\circ} \mathrm{C}$ for both DPP3T$\mathrm{L}_{0}$-TFA and DPP3T- $\mathrm{L}_{2}$-TFA of, $34 \%$ and $40 \%$ respectively, corresponded well to the theoretical mass loss of the TFA groups. However, DPP3T- $\mathrm{L}_{1}$-TFA had an additional mass loss attributed to lysine fragmentation. In comparison, DPP3T$\mathrm{C}_{8,12}$ showed no mass reduction until around $400{ }^{\circ} \mathrm{C}$ (Figure S9).

Table 3. OFET Properties of DPP3T polymers measured in BGBC Devices

\begin{tabular}{ccc}
\hline \multirow{2}{*}{ DPP3T } & \multicolumn{2}{c}{ BGBC } \\
\cline { 2 - 3 } & $\mu_{\mathrm{h}}\left[\mathrm{cm}^{2} \mathrm{~V}^{-1} \mathrm{~s}^{-1}\right]$ & $\mathrm{I}_{\text {on }} / \mathrm{I}_{\text {off }}$ \\
\hline $\mathrm{C}_{8,12}$ & $4.0 \times 10^{-2}$ & $1 \times 10^{3}$ \\
$\mathrm{~L}_{0}-\mathrm{TFA}$ & $5.7 \times 10^{-3}$ & $1 \times 10^{4}$ \\
$\mathrm{~L}_{1}-\mathrm{TFA}$ & $5.3 \times 10^{-3}$ & $5 \times 10^{3}$ \\
$\mathrm{~L}_{2}$-TFA & $1.6 \times 10^{-3}$ & $5 \times 10^{3}$ \\
\hline
\end{tabular}

Bottom gate bottom contact organic field effect transistors (OFETs) were fabricated $(L=2.5 \mu \mathrm{m}$ and $W=2000 \mu \mathrm{m})$ on ndoped $\mathrm{SiO}_{2} / \mathrm{Si}$ substrates. Representative transfer characteristics are shown in Figure 5. DPP3T- $\mathrm{C}_{8,12}$ exhibits p-type behavior with a charge carrier mobility of $4.0 \times 10^{-2} \mathrm{~cm}^{2} \mathrm{~V}^{-1} \mathrm{~s}^{-1}$ (Table 3 ), consistent with previous reports for bottom gate devices with similar molecular weight DPP3T polymer (Figure. 5a). ${ }^{21}$ DPP3T-L $\mathrm{L}_{\mathrm{m}}$-TFA films exhibited poorer hole transport properties by comparison, about an order of magnitude lower mobility for the polymers with one and two lysine units attached (DPP3T- $\mathrm{L}_{0}$-TFA and DPP3T- $\mathrm{L}_{1}-\mathrm{TFA}$ ), with a further decrease observed for DPP3T- $\mathrm{L}_{2}$-TFA. The representative output characteristics are shown in Figure S10. Consequently, these results suggest a tradeoff between favorable surface properties for cell integration and electronic properties. 

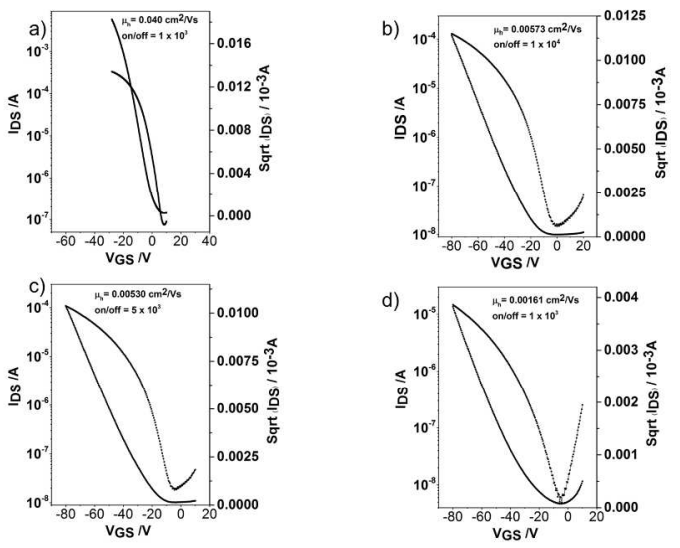

Figure 5. Transfer characteristics of OFET devices fabricated from lysinated-DPP3T polymers and DPP3T- $\mathrm{C}_{8,12}$ thin films: a) DPP3T-C ${ }_{8,12}$, b) DPP3T-L ${ }_{0}$ TFA, c) DPP3T-L $-\mathrm{L}_{1}$ TFA, d) DPP3T$\mathrm{L}_{2}$-TFA.

As device relevant films would be expected to perform at an aqueous interface, the electrochemical properties of the polymer films were characterized in a standard $0.1 \mathrm{M} \mathrm{NaCl}$ solution. Cyclic voltammetry (CV) and conductance characterization were performed using interdigitated electrodes (Figure 6a), where the polymer was spun cast between the Au coated contacts (working electrode 1, WE1 and working electrode 2, WE2). CV curves of the lysinated-DPP3T polymers and the reference DPP $3 \mathrm{~T}_{-} \mathrm{C}_{8,12}$ exhibited a common feature, i.e. a redox couple with a reduction potential of ca. $0 \mathrm{~V}$ and an oxidative potential of ca. $0.15 \mathrm{~V}$, attributed to the conjugated backbone (Figure 6b). Introduction of lysine groups increased the overall capacitance, maximized for DPP3T- $\mathrm{L}_{2}$-TFA which showed a rectangular shaped curve. Functionalized polymers exhibited more stable electrochemical behavior, evident from the similarity of the curves recorded upon successive cycles (Figure S11, dashed vs. solid lines).

Bipotentiostat measurements complement $\mathrm{CV}$ to aid further evaluate the change in conductivity of the films triggered by the electrolyte anions injected into the film, i.e., electrolyte gated transistor type behavior. For all the polymers, we observe an increase in current, therefore conductance, associated with a change in the doping state of the polymers, as the applied voltage increases above $0.5 \mathrm{~V}$ (Figure $6 \mathrm{c}$ ). The conductance is at its maximum at ca. $0.75 \mathrm{~V}$, following the oxidation peak in CVs, reaching much higher values for the lysinated polymers, e.g. $1.5 \mathrm{Scm}^{-1}$ for $\mathrm{C}_{8,12}$ and $55 \mathrm{Scm}^{-1}$ for $\mathrm{L}_{2}$-TFA. We notice also a large hysteresis between the forward and backward scans (indicated by arrows), indicating a poor reversibility of the doping process. Lysine groups render the polymer more hydrophilic (compared to the hydrophobic DPP-alkyl backbone) and therefore more permeable to electrolyte ions. Access of electrolyte ions into the bulk of the polymer in turn allows for electrochemical doping, evident from the increase in conductance and as well as the decrease in the magnitude of impedance (Figure 6d) at doping potentials. An increase in the lysine content in the composition promotes the charging capacity of the film. This also leads to the enhanced double layer capacitance observed in Figure 6b. Upon doping, $\mathrm{L}_{2}$-TFA shows the largest change in its impedance properties in agreement with its high capacitance. However, as the mobility of this polymer is the lowest, the conductance values remain

low.
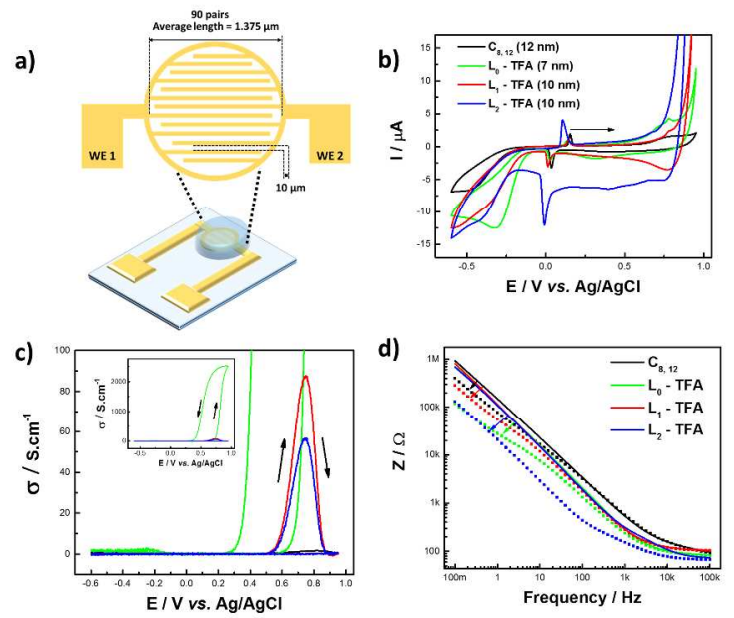

Figure 6. Electrochemical behavior of the semiconducting films. a) Schematic of an interdigitated electrode and the measurement solution (b) CV curves (scan rate $=50 \mathrm{mV} \cdot \mathrm{s}^{-1}$ ), c) in situ conductance $\left(\right.$ scan rate $\left.=10 \mathrm{mV} \cdot \mathrm{s}^{-1}\right)$, and $\mathbf{d}$ ) electrochemical impedance spectra (impedance magnitude vs. frequency) of $\mathrm{C}_{8,12}$ (black), $\mathrm{L}_{0^{-}}$ TFA (green), (4) $\mathrm{L}_{1}$ TFA (red) and (4) $\mathrm{L}_{2}$-TFA (blue) at open circuit potential ( $V=V_{\mathrm{oc}}$, solid lines) as well as at an oxidation potential $\left(V=0.26 \mathrm{~V}\right.$ vs. $V_{\mathrm{oc}}$, square symbols). The inset of $\left.\mathrm{c}\right)$ shows the full scale of conductance curves. All measurements were recorded in $0.1 \mathrm{M}$ aqueous $\mathrm{NaCl}$ solution.

The biocompatibility and the cellular adhesion promotion of the lysinated polymers were examined by monitoring neuron cell growth on polymer films as well as on a positive control, i.e., poly-D-lysine (PDL) coated coverslip, over a period of 21 days (Figure 7 and Figure S12). Both PLL and PDL offer an excellent surface coating for neurons to adhere. ${ }^{13-14}$ Cytotoxicity was determined by trypan blue assay after each culture day (see Methods). Initially, neurons aggregate or do not adhere at all on both the reference polymer $\mathrm{C}_{8,12}$ and $\mathrm{L}_{0}$-TFA (Figure 7). This is attributed to the absolute or partial lack of lysine groups on the surface. $\mathrm{L}_{1}$-TFA and $\mathrm{L}_{2}$-TFA, however, provided a suitable surface for cells to attach and grow, similar to the PDL control ( $>80 \%$ viability). On the $3^{\text {rd }}$ day of cell culture, the neuron growth is comparable on $\mathrm{L}_{1}$-TFA, $\mathrm{L}_{2}$-TFA and PLL substrates (Figure $7 \mathrm{a}$ ). On the $6^{\text {th }}$ day, however, on L${ }_{1}$-TFA surface, cells start aggregating in small clusters which interconnect over time (day 11). The growth on $\mathrm{L}_{2}$-TFA is on the other hand comparable to the PDL control. After 14 days of culture, a clear decrease in the cell density on the lysinated polymers is observed (Figure S12) as well as a decrease in the general cell viability (Figure 7b). Finally, after 21 days, small clusters on the $\mathrm{L}_{2}$-TFA surface appear, yet the network remains healthy as assessed by the relative viability assay (Figure $7 \mathrm{~b}$ ). Moreover, the network on the $\mathrm{L}_{2}$-TFA seems more developed with a higher density of connections compared to other films. 

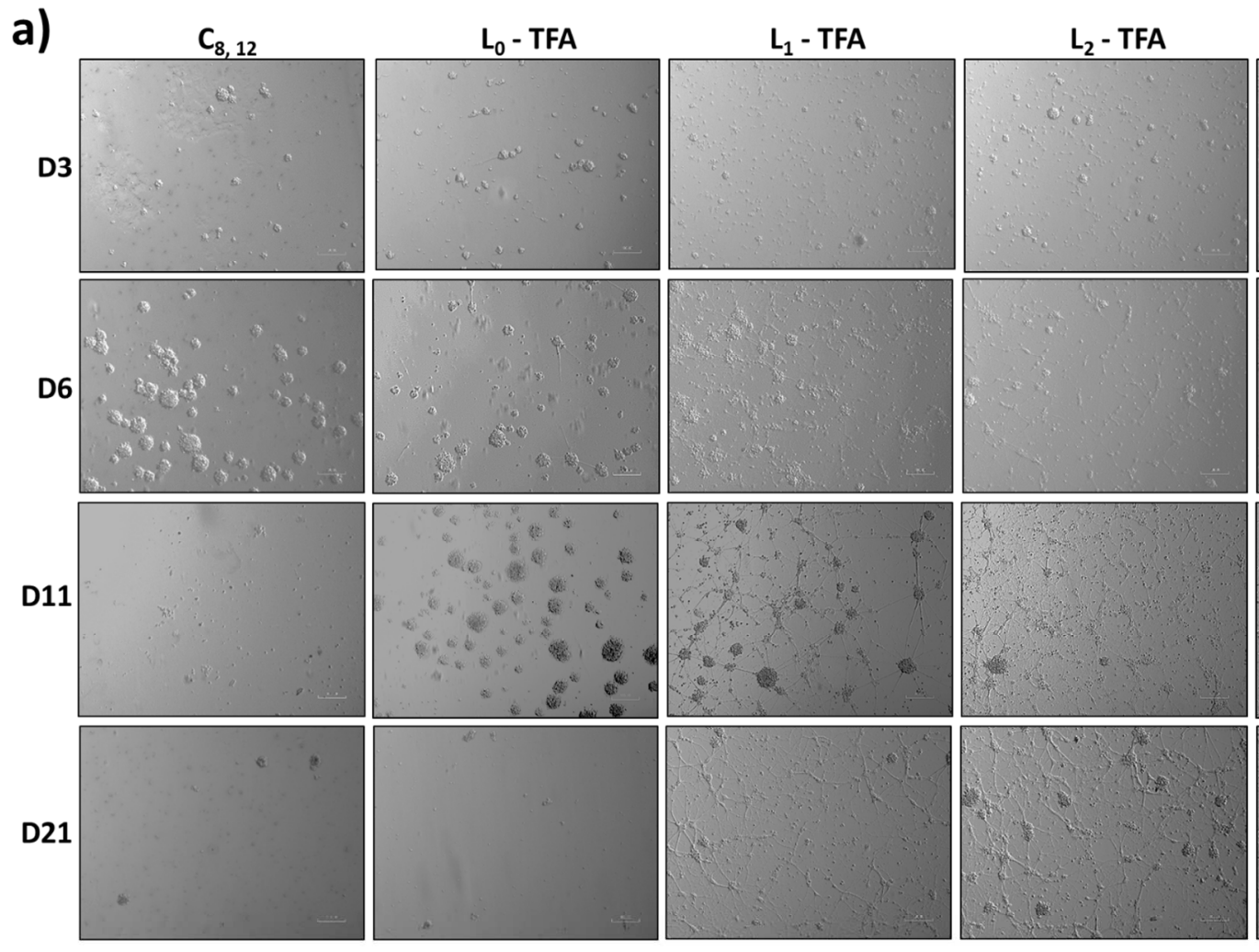

b) $\square L_{1}-$ TFA $\square L_{2}-$ TFA $\square$ PDL

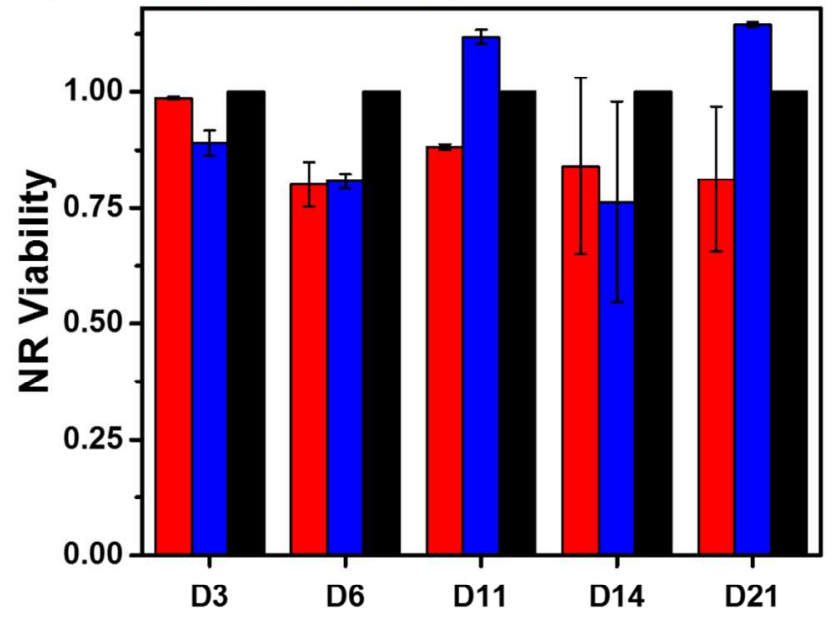

$10 \bar{\mu} \mathrm{m}$

Figure 7. Neuron cell growth and cell viability assay. a) Microscope observations of neural growth on substrates coated with $\mathrm{C}_{8,12}, \mathrm{~L}_{0}$-TFA, $\mathrm{L}_{1}$-TFA and $\mathrm{L}_{2}$-TFA compared to a substrate coated with PDL (control). The images were taken at 3, 6, 11 and 21 days of cell culture. Scale bar is $100 \mu \mathrm{m}$. b) Normalized relative (NR) viability of neurons on $\mathrm{L}_{1}$-TFA and $\mathrm{L}_{2}$-TFA compared to PDL coating

\section{Conclusion}

A series of lysine containing DPP3T polymers was synthesized. Thin film transistors were fabricated from polymer solutions and exhibited charge carrier mobilities about an order of magnitude lower than the analogous alkyl DPP3T polymer. Incorporation of lysine groups on the side chains improve the electrochemical behavior of DPP3T backbone. Lysine groups, when not in access, enable ion penetration, thereof doping of the polymer by electrolyte anions. Due to the presence of lysine groups on the surface, neurons attach, grow and form a network without the need of an intermediate PDL coating. These initial results are promising to use such biofunctionalized polymers to record/stimulate neural signals more effectively as the cells adhere to the proteinlike surfaces.

\section{Supporting Information}


Synthesis and characterization of the materials: XPS, UV-vis spectroscopy, GPC, MALDI spectrometry, TGA, OFET output characteristics, $\mathrm{CV}$ and neuron cell growth images.

\section{AUTHOR INFORMATION}

Corresponding Author

*weiyuan.du@kaust.edu.sa

\section{ACKNOWLEDGMENT}

We acknowledge funding from KAUST, as well as EPSRC Project EP/G037515/1, EP/M005143/1, ECFP7 Project SC2 (610115), for the financial support. D.O, S.I. and I.M. gratefully acknowledge financial support from the KAUST Office of Sponsored Research (OSR) under Award No. OSR-2016CRG5-3003.

\section{REFERENCES}

1. Berggren, M.; Richter - Dahlfors, A., Organic bioelectronics. Adv. Mater. 2007, 19, 3201-3213.

2. Rivnay, J.; Owens, R. M.; Malliaras, G. G., The rise of organic bioelectronics. Chem. Mater. 2013, 26, 679-685.

3. Someya, T.; Bao, Z.; Malliaras, G. G., The rise of plastic bioelectronics. Nature 2016, 540, 379-385.

4. Liao, C.; Zhang, M.; Yao, M. Y.; Hua, T.; Li, L.; Yan, F., Flexible organic electronics in biology: materials and devices. Adv. Mater. 2015, 27, 7493-7527.

5. Giovannitti, A.; Nielsen, C. B.; Rivnay, J.; Kirkus, M.; Harkin, D. J.; White, A. J. P.; Sirringhaus, H.; Malliaras, G. G.; McCulloch, I., Sodium and Potassium Ion Selective Conjugated Polymers for Optical Ion Detection in Solution and Solid State. Adv. Funct. Mater. 2016, 26, 514-523.

6. Rivnay, J.; Inal, S.; Salleo, A.; Owens, R. M.; Berggren, M.; Malliaras, G. G., Organic electrochemical transistors. Nat. Rev. Mater. 2018, 3, 17086.

7. Silvana, M.; Georgina, F.; J., d. V. L.; Anca - Dana, B.; Luminita, C.; Ioan, C.; Francesc, E.; Carlos, A., Effect of the graft ratio on the properties of polythiophene - $g$ - poly(ethylene glycol). J. Polym. Sci. B 2015, 53, 239-252.

8. Y., L. J.; E., S. C., Amine - functionalized polypyrrole: Inherently cell adhesive conducting polymer. J. Biomed. Mater. Res. A 2015, 103, 2126-2132.

9. Inal, S.; Rivnay, J.; Suiu, A.-O.; Malliaras, G. G.; McCulloch, I., Conjugated Polymers in Bioelectronics. Acc. Chem. Res 2018, $51,1368-1376$.

10. Gkoupidenis, P.; Schaefer, N.; Garlan, B.; Malliaras, G. G., Neuromorphic functions in PEDOT: PSS organic electrochemical transistors. Adv. Mater. 2015, 27, 7176-7180.

11. Khodagholy, D.; Rivnay, J.; Sessolo, M.; Gurfinkel, M.; Leleux, P.; Jimison, L. H.; Stavrinidou, E.; Herve, T.; Sanaur, S.; Owens, R. M., High transconductance organic electrochemical transistors. Nat. Commun 2013, 4.

12. Mantione, D.; del Agua, I.; Schaafsma, W.; Diez-Garcia, J.; Castro, B.; Sardon, H.; Mecerreyes, D., Poly(3,4ethylenedioxythiophene):GlycosAminoGlycan Aqueous Dispersions: Toward Electrically Conductive Bioactive Materials for Neural Interfaces. Macromol. Biosci 2016, 16, 1227-1238.

13. Sun, Y.; Huang, Z.; Liu, W.; Yang, K.; Sun, K.; Xing, S.; Wang, D.; Zhang, W.; Jiang, X., Surface Coating as a Key Parameter in Engineering Neuronal Network Structures In Vitro. Biointerphases 2012, 7, 1-14.
14. Banker, G.; Goslin, K.; Stevens, C. F., Culturing nerve cells. MIT press: 1998.

15. Bonetti, S.; Pistone, A.; Brucale, M.; Karges, S.; Favaretto, L.; Zambianchi, M.; Posati, T.; Sagnella, A.; Caprini, M.; Toffanin, S., A Lysinated Thiophene - Based Semiconductor as a Multifunctional Neural Bioorganic Interface. Adv. Healthc. Mater 2015, 4, 1190-1202.

16. Strakosas, X.; Wei, B.; Martin, D. C.; Owens, R. M., Biofunctionalization of polydioxythiophene derivatives for biomedical applications. J. Mater. Chem. B 2016, 4, 4952-4968.

17. Rao, S. S.; Winter, J. O., Adhesion Molecule-Modified Biomaterials for Neural Tissue Engineering. Front. Neuroeng 2009, 2, 6 .

18. Strakosas, X.; Sessolo, M.; Hama, A.; Rivnay, J.; Stavrinidou, E.; Malliaras, G. G.; Owens, R. M., A facile biofunctionalisation route for solution processable conducting polymer devices. $J$. Mater. Chem. B 2014, 2, 2537-2545.

19. Ohayon, D.; Pitsalidis, C.; Pappa, A.-M.; Hama, A.; Zhang, Y.; Gallais, L.; Owens, R. M., Laser Patterning of Self-Assembled Monolayers on PEDOT:PSS Films for Controlled Cell Adhesion. Adv Mater Interfaces 2017, 4, 1700191.

20. Nielsen, C. B.; Turbiez, M.; McCulloch, I., Recent Advances in the Development of Semiconducting DPP - Containing Polymers for Transistor Applications. Adv. Mater. 2013, 25, 1859-1880.

21. Zhang, X.; Richter, L. J.; DeLongchamp, D. M.; Kline, R. J.; Hammond, M. R.; McCulloch, I.; Heeney, M.; Ashraf, R. S.; Smith, J. N.; Anthopoulos, T. D., Molecular packing of highmobility diketo pyrrolo-pyrrole polymer semiconductors with branched alkyl side chains. J. Am. Chem. Soc. 2011, 133, 1507315084.

22. Han, A.; Dutta, G. K.; Lee, J.; Lee, H. R.; Lee, S. M.; Ahn, H.;

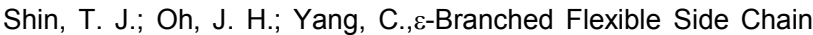
Substituted Diketopyrrolopyrrole - Containing Polymers Designed for High Hole and Electron Mobilities. Adv. Funct. Mater. 2015, 25, 247-254.

23. Rochat, S.; Swager, T. M., Water-Soluble Cationic Conjugated Polymers: Response to Electron-Rich Bioanalytes. J. Am. Chem. Soc. 2013, 135, 17703-17706.

24. Allaman, I.; Gavillet, M.; Bélanger, M.; Laroche, T.; Viertl, D.; Lashuel, H. A.; Magistretti, P. J., Amyloid- $\beta$ Aggregates Cause Alterations of Astrocytic Metabolic Phenotype: Impact on Neuronal Viability. J. Neurosci. 2010, 30, 3326-3338.

25. Tian, Y.; Kuzimenkova, M. V.; Halle, J.; Wojdyr, M.; Diaz de Zerio Mendaza, A.; Larsson, P.-O.; Müller, C.; Scheblykin, I. G., Molecular weight determination by counting molecules. J Phys Chem Lett 2015, 6, 923-927.

26. Ha, J. S.; Kim, K. H.; Choi, D. H., 2, 5-Bis (2-octyldodecyl) pyrrolo [3, 4-c] pyrrole-1, 4-(2 H, 5 H)-dione-Based Donor Acceptor Alternating Copolymer Bearing 5, 5' -Di (thiophen-2-yl)2, 2' -biselenophene Exhibiting $1.5 \mathrm{~cm} 2 \cdot \mathrm{V}-1 \cdot \mathrm{s}-1$ Hole Mobility in Thin-Film Transistors. J. Am. Chem. Soc. 2011, 133, 10364-10367.

27. Shmukler, L. E.; Gruzdev, M. S.; Kudryakova, N. O.; Fadeeva, Y. A.; Kolker, A. M.; Safonova, L. P., Thermal behavior and electrochemistry of protic ionic liquids based on triethylamine with different acids. RSC. Adv. 2016, 6, 109664-109671. 
Table of Contents

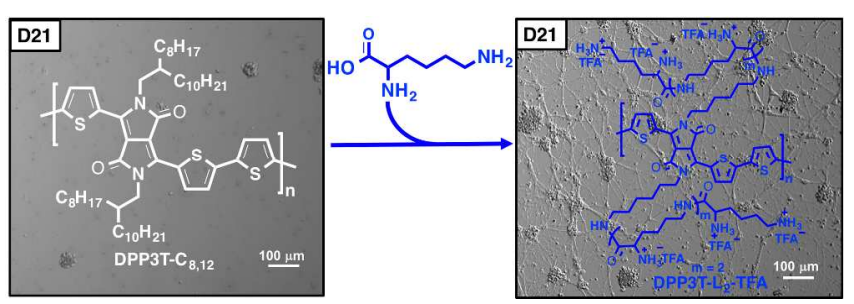

